\title{
AS CONSTRUÇÕES SOCIAIS E FÍSICAS DO RIBEIRINHO NA AMAZÔNIA
}

\author{
THE RIVERINES SOCIAL AND PHYSICAL \\ CONSTRUCTIONS IN THE AMAZON
}

\author{
LES CONSTRUCTIONS SOCIALES ET PHYSIQUES \\ DES RIVERAINS EN AMAZONIE
}

Mayra Hermínia Simões Hamad Farias do COUTO; Nirvia RAVENA; Maria Cristina de Jesus dos SANTOS.

RESUMO

A caracterização de hábitos, costumes e tradicões particulares dos ribeirinhos têm grande relevância regional, pois as cidades na Amazônia foram criadas inicialmente a partir dos rios. O objetivo da pesquisa foi descrever as construções sociais e físicas dos ribeirinhos na Amazônia com enfoque nas características e particularidades de identidade cultural na utilização do rio. A realização da pesquisa ocorreu com a análise do discurso e dados secundários utilizados para descrever e conhecer o objeto de estudo e tentar compreender o universo particular das populacões tradicionais sob a perspectiva de uma correlação a outras populacões estudadas. Foram feitas três visitas entre os anos de 2013 e 2015 com a realização de entrevistas e observação ao longo dos percursos entre as cidades de Oriximiná e Santarém, na Amazônia, avaliando a inserção cultural no contexto geográfico, econômico e político. Dividindo a população que vive na Amazônia, pode-se, de forma comparativa, distribuíla em um espaço social especifico para os ribeirinhos quando comparada aos moradores amazônicos das grandes metrópoles, pois
ABSTRACT

A characterization of habits, fantasies and particular traditions of the ribeirinhos inhabitants along the riverbanks in Amazonia - have great regional relevance, since from the rivers were the starting point for the cities in the Amazon. The objective of the research was to describe the social constructions and uses of the riverside in the Amazon, with characteristics of cultural identity in the use of the river. One research took place with an analysis of the discourse and secondary data used to describe and to get to know the object of study, and try to understand the particular universe of traditional statistics from a perspective of correlation with others studied. The researchers made three visits between 2013 and 2015 in iwhich there were interviews and observation processes along the routes between cities of Oriximiná and Santarém, in the Amazon, evaluating a cultural insertion without geographical, economic and political context. We can distribute the Amazon population in a specific social space for ribeirinhos when we compare them to the Amazonian inhabitants of the
RÉSUMÉ

La caractérisation des habitudes, des coutumes et des traditions des riverains des fleuves revêt une grande importance régionale, car les villes de l'Amazonie ont été créées initialement au bord des rivières. L'objectif de la recherche était de décrire les constructions sociales et physiques des habitants des rivières amazoniennes en se concentrant surles caractéristiques et les particularités

l'identité

culturelle. La recherche a été effectuée au moyen d'une analyse du discours et de données secondaires utilisées pour décrire et connaitre l'objet de l'étude et pour tenter de comprendre l'univers particulier des populations traditionnelles du point de vue d'une corrélation avec les autres populations étudiées en utilisation fluviale. Trois visites ont été menées entre 2013 et 2015, avec la réalisation d'entretiens et d'observations le long des itinéraires entre les villes d'Oriximiná et de Santarém, en Amazonie, afin d'évaluer l'insertion culturelle dans le contexte géographique économique et politique. Si on partage la population qui vit en Amazonie, celle-ci peut être répartie, de manière 
possuem habitus, capital econômico e cultural diferenciados, ou seja, a divisão por categorias sociais de percepcão, principios de visão e de divisão, diferenças nas práticas, nos bens possuídos e nas opiniões expressas.

PALAVRAS-CHAVES: Amazônia; Ribeirinho;Cultura; População tradicional. large cities, as they have different habitus, economic and cultural capital. That demands separating them by social categories based on perception, principles of vision and division, differences in practices, possible goods, and expressed opinions.

KEYWORDS: Amazon; Riverines, Culture; Traditional population comparative, dans un espace social spécifique aux habitants des bords du fleuve par rapport aux habitants amazoniens des grandes métropoles, car ils ont des habitus, un capital économique et culturel différents, à savoir : une division par catégories sociales de perception, des principes de vision et de division, des différences de pratiques, de possessions et d'opinions exprimées.

MOTS-CLÉS : Amazonie, Riverain Des Fleuves; Culture Population; Traditionnelle,

principalmente próximo aos rios Essa caracterização de hábitos, costumes e tradições particulares dos ribeirinhos tem grande relevância regional, pois as cidades na Amazônia foram criadas inicialmente a partir dos rios, com seus trapiches e portos. Trindade Júnior e Tavares (2008) descrevem a formação das cidades ao longo dos rios por meio de um processo histórico/geográfico vinculado à ocupação e à defesa territorial, iniciado pela igreja católica, com a criação de aldeamentos e a formação de paisagens características com uma rua principal paralela ao rio e a presença do trapiche ou porto que são geralmente precários.

Além disso, há uma forte ligação afetiva da população ribeirinha com o rio, devido à presença de populações tradicionais com origem local, o que demonstra a necessidade de identificar as características peculiares e diversificadas de habitar a Amazônia ao longo dos rios; bem como, compreender o valor simbólico dos rios aos ribeirinhos que ocupam papel central em sua cultura e
A explicação da especificidade de "denominações" para grupos específicos populacionais já vem 
tradição. Assim, o objetivo da pesquisa foi descrever as construções sociais e físicas dos ribeirinhos na Amazônia com enfoque nas características e particularidades de identidade cultural na utilização do rio.

A realização da pesquisa ocorreu com a análise de dados secundários e a pesquisa de campo. Os dados secundários foram utilizados para descrever e conhecer o objeto de estudo e tentar compreender o universo particular das populações tradicionais sob a perspectiva de uma correlação a outras populações estudadas. A pesquisa de campo teve como objetivo avaliar como o principal envolvido no objeto de pesquisa está inserido no contexto geográfico, econômico, cultural e político, já que Barros e Lehfeld (2013, p. 75) relatam que "o investigador na pesquisa de campo assume o papel de observador e explorador, coletando diretamente os dados no local (campo) em que se deram ou surgiram os fenômenos". A pesquisa ocorreu com entrevistas e observação ao longo dos percursos in loco entre as cidades de Oriximiná e Santarém, no estado do Pará, onde foram feitas três visitas às cidades e ao longo dos rios que as interliga entre os anos de 2013 e 2015. A escolha é justificada pelo percurso entre essas cidades ser exclusivo pelos rios, e ambas terem grande importância econômica, política e cultural na Amazônia. Durante a pesquisa foi feita a observação e entrevista aos atores envolvidos na dinâmica social de trocas locais, obtendo por meio da análise do discurso as características e identidade cultural do grupo social investigado dentro da perspectiva do uso dos rios.
CONSTRUÇÕES SOCIAIS DO RIBEIRINHO NA AMAZÔNIA

Ao serem considerados os espaços sociais, espaços simbólicos ou de classes sociais como um mecanismo de correlação entre sociedades, há uma necessidade de aprofundamento nas particularidades da realidade empírica e histórica situada e datada, atribuindo prioridade às particularidades de histórias coletivas diferentes, e indicando as diferenças reais que separam tanto as estruturas quanto as disposições (o habitus) para poder investigar e inferir a respeito de um grupo específico (BOURDIEU, 2011).

Assim, o conhecimento e a delimitação em grupos sociais são necessários, visto que existem muitas descrições sobre as sociedades, os grupos sociais e as civilizações com muitos pontos em comum. A conceituação de Mauss (1979), que escreveu sobre as "Civilizações: com seus elementos e formas", relaciona as civilizações ao encadeamento cronológico e geográfico das sociedades, porém utiliza o autor Adolf Bastian como o responsável pela descrição mais utilizada pelos cientistas ao agrupar em três princípios, entre eles a ideia elementar (cultural), o setor geográfico (localização) e a migração (trocas sociais). A ideia elementar se caracteriza pelo traço cultural existente entre os grupos que têm um espírito coletivo e dividem os mesmos anseios; o setor geográfico contempla as semelhanças de fatos, por línguas irmãs; e a migração é a transformação e absorção de elementos por mistura de povos. Os fenômenos de civilização se diferenciam dos fenômenos sociais, pois, por definição, fenômenos sociais são específicos de uma sociedade e responsáveis pela sua individualização e isolamento, e devem ser estudados à parte para não se cometer erros, pois todos têm uma característica importante, a de serem comum a uma parte da sociedade e inclusos em sua história definindo assim os fenômenos de civilização. Lakatos (1997) corrobora ao definir que sem os grupos sociais não seria possível compreender a evolução da sociedade e que são unidades fundamentais e elementares formadas a partir da coletividade de pessoas que desempenham papéis recíprocos, segundo determinadas normas, interesses e valores sociais visando o mesmo objetivo, porém as características desses grupos compreendem a identificação por membros internos (pertencentes) e externos, pela estrutura social, devido a diferenciação dos papéis individuais, das relações recíprocas, das normas comportamentais, do interesse e valores comuns, da finalidade social e da permanência. Somam-se as influências sobre os indivíduos dentro de um mesmo grupo que determinam atitudes, formam opiniões, fornecem um "meio" de conhecer a realidade, e ajudam a formar uma perspectiva de vida. As influências citadas acima pelo autor, poderiam ser justificadas pelo poder simbólico descrito por Bourdieu (2012) que faz agrupar pessoas em um mesmo grupo social.

Ao inferir sobre os fenômenos sociais e avaliar os dialetos, a constituição, o costume religioso ou estético e a moda, 
pode-se concluir a existência de uma força simbólica na delimitação da sociedade e de grupos. Faz-se uma analogia ao poder simbólico, em que Bourdieu (2012) descreve a comunicação como fenômeno social que delimita uma sociedade ou civilização, ao ser capaz de transmitir conhecimento e promover as relações sociais com o poder simbólico de repassar significação à informação. Desse modo, o ponto principal de trocas sociais dos ribeirinhos é delimitado por o usufruto de uma territorialidade de ocupação e pertencimento ao longo dos rios, organizando-os em grupos sociais com uma comunicação própria de valor simbólico (re)conhecida por essa comunidade tradicional.

Assim, os fenômenos sociais são responsáveis por imprimir características únicas a uma determinada sociedade; enquanto são descritos os "fenômenos de civilização" a partir de fenômenos sociais que possuem características de semelhanças com um número maior ou menor de sociedades e de um passado mais ou menos distante dessas sociedades, podendo ser divididos conforme o tempo e o lugar e que se transmitem de grupo a grupo, de geração a geração e são conceituados como: "aqueles fenômenos sociais comuns a várias sociedades mais ou menos próximas" (MAUSS, 1979, p. 186). Dessa forma, as populações tradicionais como as

ribeirinhas, foram ao longo de muitos anos incompreendidas e rotuladas erroneamente como uma sociedade "não" civilizada, porém nota-se as características peculiares e exclusivas que as categorizam dentro de seus fenômenos sociais em uma sociedade civilizada por sua forma organizada de interagir regida por suas regras de conduta.

Mauss (1979, p. 186-187) propõe como definição de civilização:

Éum conjunto
suficientemente
grande numeroso
de fenômenos de
civilizacão, os quais
devem ser
suficientemente
importantes, tanto
pela quantidade como
pela qualidade; é
também um conjunto
bastante vasto de
sociedades que os
apresentam;
outras palavras: um
conjunto
suficientemente
grande
suficientemente
característico para
que possa significar,
evocar uma familia de
sociedade (MAuss,
1979,p. 186-187)

A civilização descrita por Durkheim e Mauss (2013) aponta a existência de sistemas complexos e solidários, localizáveis no tempo e no espaço e constituídos de uma espécie de meio ambiente moral por meio da atuação de suas particularidades e de organismos sociais dominando a vida coletiva de cada povo, em resumo, é responsável por exprimir uma vida coletiva de um gênero especial. Um dos exemplos apontados é a linguística, que agrupa as sociedades em famílias de povos que estão ou estiveram em relação com os outros ou que saíram de uma mesma origem refletindo nas instituições geradas por elas.
Roué (1997) aponta o valor simbólico da língua para uma sociedade como responsável por determinar seu próprio caráter perceptual, com uma grande riqueza e complexidade de vocabulário. As populações tradicionais na Amazônia, incluindo os ribeirinhos, são identificados como um grupo ao denominarem de forma única e específica seus materiais de uso comum, como a nomeação de embarcações pequenas que podem variar pelo tamanho, material com que são feitos, o uso e a força do motor, podendo ser descritos como "rabeta", "catraia", "pô-pô-pô" e outras que encontram um significado aos que deles utilizam. Este fato é confirmado por Castro (1997), que relata que os sistemas classificatórios das populações tradicionais são obtidos pelo vocabulário e termos usados na vivência e na adaptação aos ecossistemas.

As trocas sociais geradas pelos dialetos também ocorrem a partir de costumes. A formação de instituições e costume religiosos peculiares ao local e de origem comum, perpassada ao longo dos tempos, também aparece como uma característica dos ribeirinhos que os transforma em grupo. Como exemplo, a figura do padre, ou hoje também do pastor, como o "dono do conhecimento" e da instrução para as tomadas de decisões que tem sua localização principalmente as margens dos rios na Amazônia; assim como a aproximação social e o lazer que ocorrem em festejos religiosos e por meio das "conversas" na frente do rio. Os mirantes, os cais, os trapiches e as praças sempre margeados pelos rios, podendo ter também outras denominações, funcionam como 
um ponto central de encontro para os ribeirinhos que a partir desse local desenvolvem suas trocas impulsionadas por costumes perpassados por gerações.

Com isso, pode-se abordar os grupos ou classes sociais no espaço social a partir de uma distribuição dos grupos em função de sua diferenciação de capital econômico e o capital cultural. Cada espaço social de posições corresponderia a uma classe vinculada por afinidade de estilos, ou seja, de gostos (habitus) produzidos por condicionamentos sociais com valores simbólicos. É apontado que a proximidade no espaço social é o que agrupa a sociedade em classes sociais gerando as práticas culturais, de consumo, de opiniões políticas etc.; e está organizada em três dimensões fundamentais distribuídas pelo volume global de capital, a estrutura desse capital e com a evolução desse capital (BOURDIEU, 2011).

Ao dividir a população que vive na Amazônia, pode-se, de forma comparativa, distribuí-la em um espaço social específico para os ribeirinhos quando comparada aos moradores amazônicos das grandes metrópoles, pois possuem habitus, capital econômico e cultural diferenciados, ou seja, a divisão por categorias sociais de percepção, princípios de visão e de divisão, diferenças nas práticas, nos bens possuídos e nas opiniões expressas. Diegues (1997), ao escrever a forma de utilização da Amazônia, diferencia as populações por meio de seus interesses e saberes, classificando as populações em urbanoindustriais e tradicionais a partir do uso da terra, cuja população tradicional a utiliza de forma coletiva como um direito sagrado onde viveram seus antepassados que thes fornece os meios de subsistência, os meios de trabalho e produção e os meios de produzir os aspectos materiais das relações sociais, com o rio assumindo o papel de protagonista, enquanto as populações urbanoindustriais compreendem o uso da terra como privado, dividindo-os assim em dois grupos diversos.

Porém, mesmo a categorização em grupos deve ser cuidadosamente descrita. Popper (2013) descreve como enunciados "específicos" ou "singulares" os que dizem respeito apenas a certas regiões finitas do espaço e do tempo e diferencia os conceitos universais e individuais, em que os enunciados singulares da ciência aparecem, frequentemente, em coordenadas espaço-temporais, podendo ser conceitos de classes, enquanto os enunciados universais remetem ao todo. Dentro da abordagem de Popper(2013), os ribeirinhos se inserem num enunciado específico ou singular, já que se categorizam num padrão específico e único dentro de uma coordenada espaçotemporal, incluindo assim, as características sazonais de organização.

Na Amazônia, há diversas formas de usufruto dos rios que depende da sazonalidade para obter certos recursos, como o provimento de certos alimentos, entre eles os variados peixes, as coletas extrativistas ou o cultivo da agricultura de subsistência ${ }_{1}$ que precisam dos fluxos das águas dos rios para seu consumo. Outra forma de acesso aos recursos é observada com o transporte fluvial que utiliza variadas tipologias de embarcações, e para os ribeirinhos é a principal forma de deslocamento, o que demonstra sua relevância a essa população tradicional. $\mathrm{Na}$ Amazônia foram observados índices alarmantes de acidentes com o motor das embarcações que causam a perda de cabelos (escalpelamento) ou a morte de usuários; ocorre quando as vítimas têm seus cabelos repentinamente puxados pelo eixo do motor de embarcações, arrancando bruscamente todo ou parte do couro cabeludo da vítima, inclusive orelhas, sobrancelhas e por vezes uma enorme parte da pele do rosto e pescoço, levando a deformações graves e até a morte (CAPOR, 2014). Nas entrevistas colhidas ao longo da pesquisa, uma ribeirinha que sofreu o escalpelamento com sete anos narrou a experiência vivenciada por ela e sua família.

Na manhã de um dia desconhecido no ano de um mil novecentos e noventa e seis, uma família ribeirinha navegava em direção a sua residência no rio Inhamundá no estado do Pará. O percurso transcorreria aproximadamente quatro horas de viagem na própria embarcação da família, quando a filha caçula foi ao "bacio" (penico) e parte de seu cabelo foi arrancado pelo eixo do motor da embarcação. A família foi atendida na unidade de saúde da cidade mais próxima, no entanto, foi encaminhada com urgência para uma cidade de maior porte (Oriximiná-PA) em lancha paga pela prefeitura. Na manhã seguinte a criança e sua mãe foram de avião para a capital, Belém (PA), sendo atendidas no hospital de 
referência (Santa Casa de Misericórdia), onde ficou em tratamento por quatro meses em contato com sete crianças que também haviam sofrido o escalpelamento. Após tratamento, retornou a sua casa e permaneceu um ano sem freqüentar a escola, quando apresentou anemia e voltou para Belém, onde fez enxertia do couro cabeludo, melhorando o aspecto local. escalpelamento é capaz de impactar uma família dentro de vários enfoques, culturalmente pela perda dos longos fios e sua mutilação que gera o menor "embelezamento" para o grupo social, economicamente pela diminuição na oferta de recursos, psicologicamente pelos traumas gerados e socialmente pela diminuição de contato gerado pelo isolamento, e na Amazônia, ainda é uma das principais externalidades negativas aos ribeirinhos.

No entanto, o uso das águas fluviais é imprescindível para essa população tradicional que utiliza esse território de pertencimento com técnicas corporais específicas em suas atividades cotidianas (SILVEIRA; BASSALO, 2012) e são justificadas a partir do valor simbólico em que a cultura de um povo emprega nas características gerais de comportamento, inclusive as corporais (MAUSS, 2003; BOURDIEU, 2012). Assim, devese ter em mente a história vivenciada por seus habitantes que passada por gerações, impactam o seu modo de vida. No caso da Amazônia, a forma de ocupação a partir dos leitos dos rios, primeiramente com a colonização, depois com a urbanização dessas localidades que originaram as cidades.

CONSTRUÇÕES FÍSICAS DO RIBEIRINHO NA AMAZÔNIA
Um exemplo prático que pode ser usado comparativamente aos ribeirinhos, guardando suas devidas proporções, foi a descrição das variações sazonais das sociedades esquimós feita por Mauss (2003), que aponta como um campo de estudo privilegiado já que além de ser uma população geograficamente determinada, sofre ao longo do ano grandes modificações conforme as estações, modificando a maneira como os homens se agrupam, a forma de suas casas, a natureza de suas instituições e aponta que afeta os diferente modos de atividades coletivas. Assim como os esquimós, os ribeirinhos são essencialmente um povo que vive à margem d'água, e para ambos, a forma de interação com sua moradia se modifica sazonalmente de acordo com a cultura local e as necessidades sazonais. Para os esquimós, a habitação no verão é feita em uma construção mais simples composta de varas em formato de cone que não comporta divisórias para isolar a família de seus eventuais hóspedes, dormindo todos em um mesmo ambiente, chamada de tenda, enquanto que a habitação no inverno é chamada de casa e possui três elementos essenciais; um corredor que começa no exterior e vem desembocar no interior por uma entrada subterrânea; um banco com lugares para lâmpadas e divisórias que determinam 0 compartilhamento de ambiente, muito conhecido como iglu. Essas diferenças habitacionais ocorreram por meio de um desenvolvimento histórico provavelmente muito longo e de migrações de extraordinária amplitude (MAUSS, 2003).

Porém, para o ribeirinho, a sazonalidade ocorre com a cheia e a seca do rio, modificando as habitações das pessoas que vivem nas proximidades dos rios em que o volume e a altura das águas se modificam. Resumidamente, as habitações podem se localizarem terrenos que não são alagados com o aumento de volume de água e assim não "invadem" o limite da casa, sendo denominada pela população local como casas em "terra firme", esses são os terrenos que abrigam os animais que são transportados com a cheia. Porém, as casas localizadas em terrenos que são submersos durante a cheia, são feitas de "palafitas", ou seja, casas em cima de estruturas de madeira sem tocar o chão, e o acesso aos rios ou ao solo, quando em época de seca, é feito por escadas ou terminais flutuantes privados, como observado nas Fotografias 1 e 2.

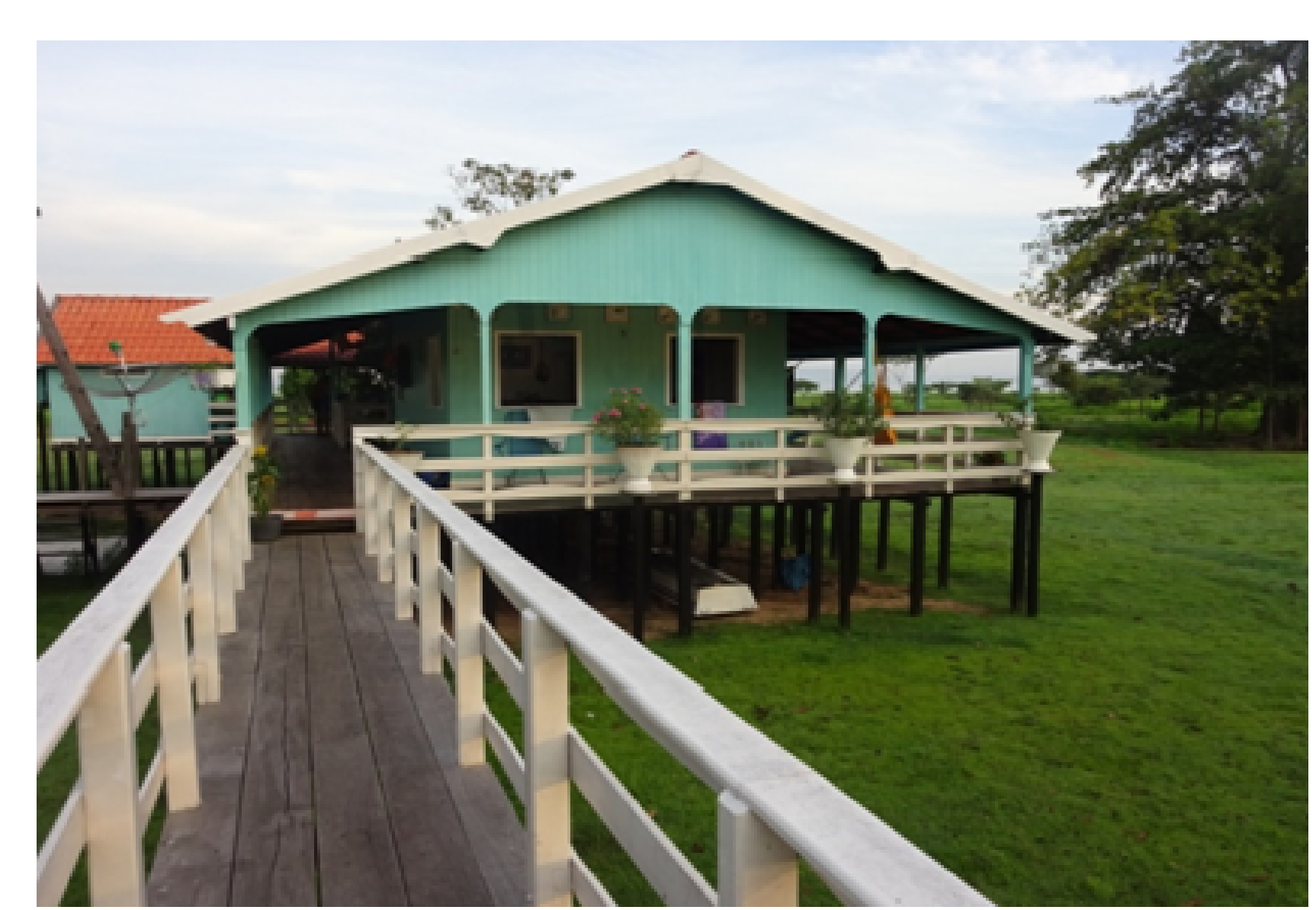

Fotografia 1 - Casa de palafita.

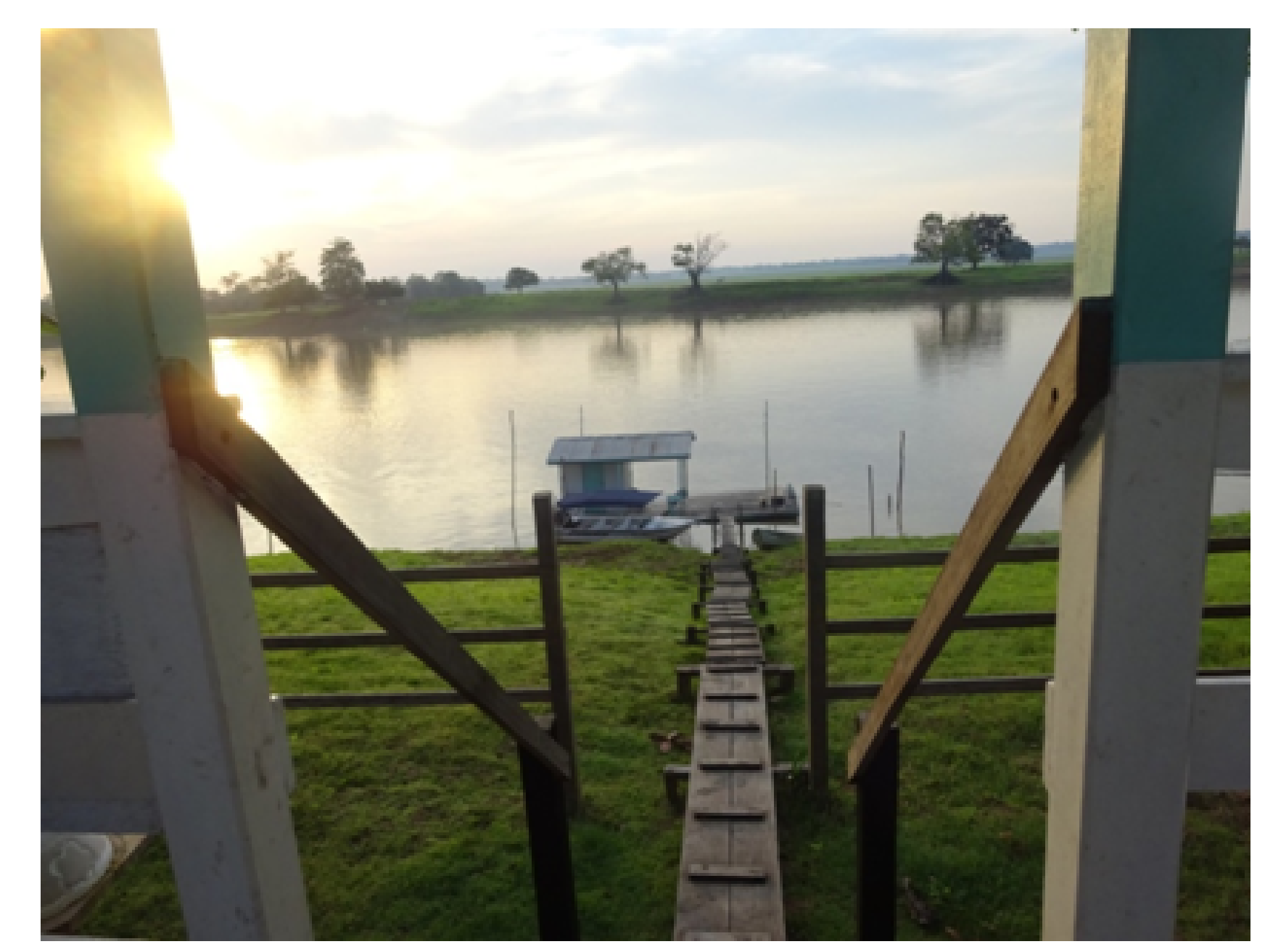

Fotografia 2 - Vista do caminho de uma casa de palafita ao solo ou rio.

Existem também algumas casas flutuantes que são usadas quando a altura da água excede o limite esperado, e a flutuação de alguns domicílios é feita por estruturas hermeticamente fechadas com ar dentro que são colocadas por baixo do chão de 
madeira das casas e podem ter grande variedade de materiais e formatos, porém na maioria das vezes reutilizam-se garrafas plásticas em casas ou terminais flutuantes menores como observado na Fotografia 3 que mostra um flutuante como terminal de embarque e desembarque de embarcações. Contudo, podem possuir estruturas diferenciadas, como na Fotografia 4 que mostra dois tubos de alumínio apoiando a casa.

Essas casas flutuantes podem ser deslocadas ao longo dos rios, podendo ser recolocada em um local de "terra firme" e servem como terminais de embarque e desembarque, comprovando sustentabilidade por meio de conhecimentos acumulados que perpassam as gerações nas escolhas feitas

pelos ribeirinhos. Acevedo Marin e Castro (1998) contribuem com a investigação ao descrever as relações socioambientais de comunidades ribeirinhas com a natureza que fazem parte:" $A$ ordem da natureza é interpretada seguramente sem o rigor de um conhecimento produzido pela ciência, mas gerador de um saber prático eficiente em relação ao seu modo de produzir e viver". (ACEVEDO MARIN; CASTRO, 1998, p. 169).



Fotografia 3 - Casa flutuante feita com garrafas plásticas.

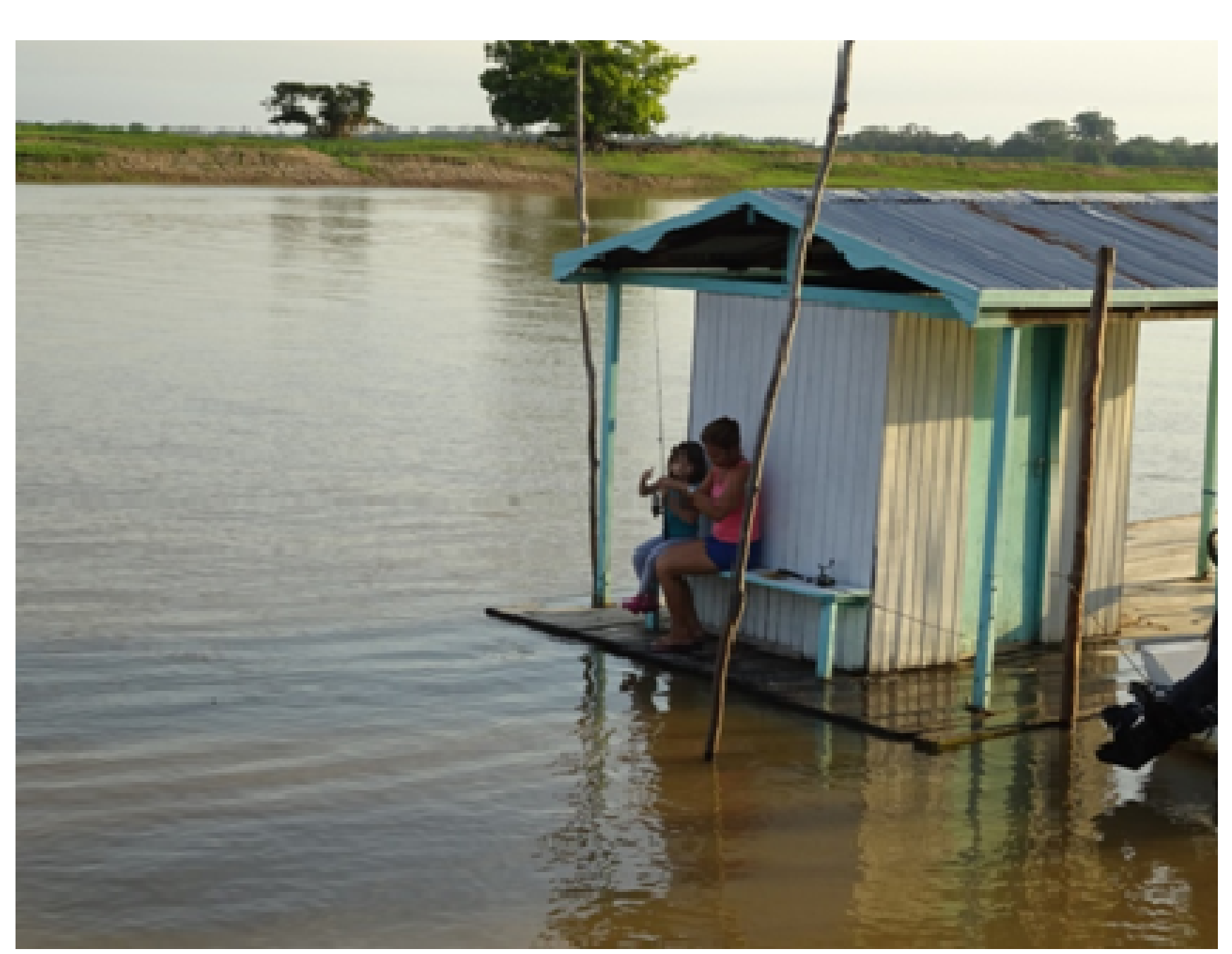

Fotografia 4 - Casa flutuante feita com estrutura de alumínio.

Além de modificar a forma de habitação, a sazonalidade, descrita a partir das águas, também contribui nas variadas atividades produtivas agroextrativista. Scherer (2004) descreve os modos de vida dos ribeirinhos a partir de dois ecossistemas, as terras de várzeas, sujeitas a inundações nas cheias e as terras firmes, que não inundam com as mudanças sazonais e servem de apoio. Assim estes são chamados de povos das águas, por viverem em função das mudanças sazonais que regulam suas atividades; viverem em pequenas comunidades próximas aos rios em casas de palafita; usarem a terra para a agricultura familiar e o extrativismo de produtos regionais e o rio como principal fonte proteica, no entanto, o excedente é vendido e comprase carne bovina.

Ao estudarem a população negra nas margens do rio Trombetas, Acevedo Marin e Castro (1998) descreveram as atividades produtivas e sua maneira de realizá-las a partir de uma divisão entre verão e inverno, equivalente respectivamente à "seca" e "cheia" dos rios. No inverno aumenta-se a coleta dacastanha e a caça é priorizada por estar mais gorda, enquanto que na época do verão, o trabalho na roça é intensificado e o peixe é mais consumido. As autoras também relacionaram a sazonalidade a partir do volume d'água com as manifestações sociais, capaz de promover a organização do calendário anual de festas e religiosidades, de manifestações políticas, de maior ou menor integração nas relações familiares.

Paiola e Tomanik (2002) apontam, por meio de suas entrevistas com pescadores, que as populações tradicionais se identificam não só pelas características descritas por Diegues (1996) como, por exemplo, pelo apego ao estilo livre de vida, dependência e conhecimento aprofundado em relação aos ciclos naturais, importância dada à unidade familiar, reduzida acumulação de capital, utilização de tecnologias simples e fraco poder político, mas também por serem descendentes e herdeiros de população e cultura tradicionais.

Não se deve esquecer que mesmo dentro do conceito de populações tradicionais encontramos as particularidades de etnias, costumes, manejo da terra e do rio e outras formas de interação com o ambiente. No entanto, a tradição indígena por meio de técnicas e estratégias de manejo foi a primeira fonte cultural das populações tradicionais e originou a descoberta de alimentos e matérias-primas importantes usados ainda hoje por todos, como a batata, a mandioca, o milho, a borracha, o guaraná etc., o que demonstra que os índios são responsáveis pelo saber primitivo na

América,porém ainda não muito valorizado pela população urbano-industrial PEREIRA, 2007). 
Diegues e Arruda (2001) consideram as populações tradicionais como indígena e não indígena, porém algumas não indígenas (caiçara, ribeirinho amazônico, sertanejo) receberam forte influência indígena observada na herança dos termos regionais e nas tecnologias patrimoniais de preparação de alimento, cerâmica e técnicas de construção de instrumentos de caça e pesca. As populações tradicionais não indígenas foram ordenadas de acordo com "áreas culturais", diferenciandoas em: açorianos, babuaçeiros, caboclos / ribeirinhos amazônicos, caiçaras, caipiras / sitiantes, campeiros (pastoreio), jangadeiro, pantaneiro, pescadores artesanais, praieiros, quilombolas, sertanejos / vaqueiros e varjeiros (ribeirinhos não amazônicos).

A definição de populações tradicionais não indígenas da Amazônia é caracterizada pelas atividades extrativistas aquáticas ou florestais terrestres. O caboclo / ribeirinho amazônico é extrativista, mas vive da pesca nas várzeas e nas beiras de

igarapés, igapós, lagos e rios e sua vida é regulada pelos ciclos da água modificando as atividades de extrativismo vegetal, agricultura e pesca. O modo de produção agrícola é familiar, vendendo o excedente e trocando com os vizinhos; se utilizam de seus conhecimentos sobre a várzea na colheita de produtos alimentícios, como mandioca, frutas e ervas medicinais; na floresta extraem o látex e a castanha-do-pará; criam pequenos animais domésticos e possuem poucas cabeças de gado; moram em casas de madeira construídas em palafita; a pesca é importante fonte de proteína e renda; e a crença em diversos seres sobrenaturais tem influência sobre a caça e a pesca (DIEGUES; ARRUDA 2001).

\section{CONSIDERAÇÕES FINAIS}

Essa ocupação e utilização dos recursos no território amazônico ocorrem a partir da interação com o meio ambiente de forma específica por seus povos por meio dos conhecimentos integrados de crenças e práticas passados por gerações, mas sempre ao entorno das redes de trocas fluviais na Amazônia (CASTRO, 1997; DIEGUES, 2000; DIEGUES, 2001; LIMA; PEREIRA, 2007). E OS ribeirinhos fazem das ilhas seus territórios-paisagens de pertencimento pela caracterização de território e o uso de seus recursos em que a sazonalidade atua na adaptação ao meio em que usufruem, como em sua moradia e embarcação. Somado a sua forma característica, peculiar e diversificada de habitar a Amazônia ao longo dos rios com uma multivariada incorporação de técnicas e ajustes ao espaço, possuem sua própria, exclusiva e diferenciada identidade cultural.

A diferenciação da forma de interagir com o meio é então uma das características e particularidades de identificar culturalmente os ribeirinhos dentro de suas construções sociais e físicas, sendo os ribeirinhos, um dos atores amazônicos inclusos no grupo de populações tradicionais. Para isso, começaram os estudos dos saberes da natureza das populações locais ou indígenas a partir de 1970, na perspectiva de valorizar esses saberes para gerir recursos naturais, com enfoque na preservação do ecossistema e biodiversidades, reconhecendo na esfera científica e política o direito do povo de dispor deles mesmos (CASTRO, 1997; DIEGUES, 1997; PAIOLA; TOMANIK, 2002; ROUÉ, 1997), como na utilização do rio como um bem comum a partir da identidade cultural atribuída a ele, e assim, assumindo a busca de reconhecimento desse grupo dentro do espaço amazônico a partir de suas peculiaridades culturais. Diegues acrescenta que a exploração dos recursos naturais pelas populações tradicionais ocorre mediante as relações sociais, suas racionalidades intencionais, seus objetivos de produção material e social por meio de representações simbólicas, e o rio assume aos ribeirinhos o valor simbólico indispensável à sobrevivência.

Somado a essa caracterização de identificação cultural, Furtado (2009) aponta a necessidade de valorização do ser humano em sua diversidade sociocultural e adaptativa com enfoque na relação dos pescadores com os rios que envolvem valores, concepções, interesses e objetivos sobre os patrimônios naturais carregados de semântica, pois além de ser fonte de alimento e provisão de água, têm os significados que extrapolam a natureza material e quase sempre são invisíveis ao senso comum. Visto que, nas sociedades primitivas e tradicionais existe uma ligação próxima entre o homem e a natureza, marcada por crenças em mitos ancestrais e religiososcomo um sistema de representação da natureza, na qual o rio exerce três funções de conhecimento e significação aos ribeirinhos, sendo elas a representação, a organização e a legitimação nas relações de pertencimento na natureza vivenciada (DIEGUES, 1997).

Assim, propõe-se O 
reconhecimento da existência de um saber das populações tradicionais, igualmente racional ao conhecimento científico da ciência moderna, capaz de compreender e conservar a biodiversidade por meio do manejo sustentável. O saber técnico-científico não pode "desqualificar e desvalorizar todos os outros saberes e práticas", haja vista que os grupos humanos, ao desempenharem suas atividades produtivas misturam formas materiais e simbólicas por meio de aspectos visíveis e invisíveis, bem como as populações tradicionais que reúnem os elementos técnicos com o simbólico, por intermédio do mágico e dos rituais (CASTRO, 1997; SOUZA, 2017; OLIVEIRA, 2019).

Para as populações tradicionais na Amazônia, o rio sempre é o gerador das relações sociais, seja por saberes tradicionais, por manejo, por usufruto do espaço, por contato e troca, entre outros, o que demonstra a necessidade indispensável da proteção das construções sociais e físicas do ribeirinho na Amazônia dentro de sua abordagem peculiar de identificação cultural a partir dos rios.

\section{REFERENCIAS}

\section{ACEVEDO MARIN, ROSa}

Elizabeth; CASTRO, Edna.

Negros do Trombetas:

Guardiães de matas e rios. 2. ed. Belém: Cejup;UFPA;NAEA, 1998

BARROS, A. J. P.; LEHFELD, N.

A. S. Projeto de pesquisa: propostas metodológicas. 13. ed. Rio de Janeiro: Vozes, 2013

\section{BOURDIEU, Pierre. Razões}

Práticas: sobre a teoria da ação. 11. ed. Campinas: Papirus, 2011.

\section{O mito do paraíso}

O poder simbólico. 16.

ed. Rio de Janeiro: Bertrand

Brasil, 2012

\section{CAPITANIA DOS PORTOS DA}

AMAZÔNIA ORIENTAL

(CAPOR). Palestra de prevenção ao escalpelamento. Belém, 2014.

Disponivel em: <https://

www.mar.mil.br/cpaor/arquivos

lescalpelamento.pdf>. Acesso

em: 10 jan. 2015

CARVALHO, J.E.C. Os grupos nome: efeitos da substituição do imaginário pelo virtual na constituição dos grupos sociais Psicologia e Sociedade; 14 (1)

28-43; jan./jun.2002.

CASTRO, Edna. Território, biodiversidade e saberes de populações tradicionais. In: CASTRO, Edna E.; PINTON, Florence. Faces do trópico úmido:conceitos e novas questões sobre desenvolvimento e meio ambiente. Belém: Cejup; UFPA:NAEA, 1997.

\section{DIEGUES, A. C. S. O Mito}

Moderno da Natureza Intocada. São Paulo: Hucitec, 1996.

POPPER, Karl Raimund. A lógica da pesquisa científica. 2. ed. São Paulo: Cultrix, 2013. desabitado nas florestas tropicais brasileiras. In: CASTRO, Edna E.; PINTON,

Florence. Faces do trópico úmido: conceitos e novas questões sobre desenvolvimento e meio ambiente. Belém: Cejup; UFPA;NAEA, 1997.

\section{Saberes tradicionais e} etnoconservação. In: DIEGUES, Antonio Carlos; VIANA, Virgílio M. Comunidades tradicionais e Manejo dos recursos naturais da Mata Atlântica. São Paulo. HUCITEC;NUPAUB-CEC/USP, 2000.
DIEGUES, Antonio Carlos, ARRUDA, Rinaldo S. V. Saberes tradicionais: biodiversidade no Brasil. Brasilia: Ministério do Meio Ambiente; São Paulo: USP 2001. 176 p.

DURKHEIM, É., MAUSS, M. Algumas Formas Primitivas de Classificação (1903). In: MAUSS M. Ensaios de Sociologia. São Paulo: Ed. Perspectiva, 2013.

FURTADO, Lourdes Goncalves. Comunidades tradicionais: sobrevivência e preservação ambiental.In: D'INCAO, M. A. SILVEIRA, I. M. (Org.). A

Amazônia e a crise da modernização. 2. ed. Belém: Museu Paraense Emilio Goeldi, 2009. p. 67-74.

GAMA, A. S. M et. al. Inquérito de saúde em comunidades ribeirinhas do Amazonas, Brasil. Cadernos de Saúde Pública (CSP),v. 18, n.02, p. 1-16, 2018

LAKATOS, Eva Maria. Introdução a sociologia. São Paulo: Atlas, 1997.

Sociologia e

Antropologia. São Paulo: Cosac Naify, 2003.LIMA, Marta Goreth Marinho; PEREIRA, Elves Marcelo Barreto. Populações tradicionais e conflitos territoriais na Amazônia. Belo Horizonte: Geografias, v, 3, n.7, p.107-119, jan./jun., 2007.

MAGALHÃES, Marcos Pereira. Território cultural e a transformação da floresta em artefato social. Boletim do Museu Paraense Emílio Goeldi. Ciências Humanas, v. 8, n. 2, p. 381-400, maio-ago. 2013.

MAUSS, Marcel. Antropologia. São Paulo: Ática, 1979.

Organizador da Coletânea: Roberto de Cardoso Oliveira. 
OLIVEIRA, José Alcimar de. Amazônia, natureza e cultura: para além da medida do conhecimento baconiano e da dicotomia epistemológica cartesiana, funcionais ao sistema do capital. Revista Atlante: Cuadernos de Educación y Desarrollo, mai, 2019.

PAIOLA, Lucy Mara; TOMANIK, Eduardo Augusto. Populações tradicionais, representações sociais e preservação ambiental: um estudo sobre as perspectivas da continuidade da pesca artesanal em uma região ribeirinha do rio Paraná. Acta Scientiarum, Maringá, v. 24, n.1, p. 175-180, 2002.

ROUÉ, Marie. Novas perspectivas em etnoecologia. "saberes tradicionais" e gestão de recursos naturais. In: CASTRO, Edna E.; PINTON, Florence. Faces do trópico úmido: conceitos e novas questões sobre desenvolvimento e meio ambiente. Belém: Cejup;UFPA;NAEA, 1997.

SCHERER, Elenise. Mosaico Terra-Água: A vulnerabilidade social ribeirinha na Amazônia Brasil. In: CONGRESSO LUSOAFRO-BRASILEIRO DE CIENNCIAS SOCIAIS - CES, 7., [Anais...] Coimbra, 2004. Disponivel em <http://www.ces.uc.pt/lab2004 /pdfs/EliseScherer.pdf>. Acesso em: 15 maio 2015

SANTOS, Leandra

InesSeganfredo; et. al. Pesquisa linguística na Amazônia brasileira: Integrar para fortalecer. Araguaina/TO: Entreletras, v. 10, n. 1, jan/jun 2019.
SOUZA, Deise Nilciane Ferreira de. Um outro senso comum: Práticas socioambientais entre os ribeirinhos do baixo amazonas. Revista Nova Hileia. Vol. 3. № 1, jul-dez 2017.

SILVEIRA, Flávio Leonel Abreu da; BASSALO, T. F. R. Corpos em equilibrio: imagens $\mathrm{e}$ cotidiano ribeirinho no Porto do Açai e na ilha do Maracujá em Belém (PA). 2012.

(Apresentação de Trabalho/Comunicação).

TRINDADE JÚNIOR, Saint-Clair Cordeiro da; TAVARES, M. G.

CidadesRibeirinhas na

Amazônia: mudanças e permanências. Belém: UFPA, 2008.

ZANELLA, Andréa Vieira; PRADO FILHO, Klébe; ABELLA, Sandra Iris Sobrera. Relações sociais e poder em um contexto grupal: Reflexões a partir de uma atividade específica. Estudos de Psicologia. vol 8 (1),p. 85-91, 2003.

Disponivel em:

<http://www.scielo.br/pdf/epsc /v8n1/17238.pdf>. Acessado em: 20 de agosto de 2019. 
Recebido em 01 nov 2019 | Aprovado em 03 dez 2019

Mayra Hermínia Simões Hamad Farias do COUTO

Doutora em Desenvolvimento Sustentável do Trópico Úmido pelo Núcleo de Altos Estudos da Amazônia (NAEA) da Universidade Federa do Pará (UFPA). Mestre em "Neurociências e biologia celular" pela Universidade Federal do Pará (UFPA) Especialista em "Fisioterapia em Neurologia" pela Universidade Metodista de São Paulo (UMESP) e em "Métodos de tratamento em deficiências físicas e gestão organizacional de centros de reabilitação" pela Associação de Assistência à Criança Deficiente (AACD) e Instituto da cabeça da Universidade Federal de São Paulo (UNIFESP). Graduada em Fisioterapia pela Universidade da Amazônia (UNAMA)

E-mail: mayrahamad@gmail.com

\section{Nírvia RAVENA}

Doutora em Ciência Política (Ciência Política e Sociologia) pelo Instituto Universitário de Pesquisas do Rio de Janeiro (IUPERJ). Mestre em Planejamento do Desenvolvimento pela Universidade Federal do Pará (UFPA). Graduada em Ciências Sociais pela Universidade Federal do Pará (UFPA). Atualmente, é professora do Programa de Pós-Graduação em Desenvolvimento Sustentável do Trópico Úmido (PPGDSTU) do Núcleo de Altos Estudos Amazônicos (NAEA), e pesquisadora do Instituto Nacional de Ciência e Tecnologia em Políticas Públicas, Estratégias e Desenvolvimento (INCTPPED).

E-mail: niravena@gmail.com

Maria Cristina de Jesus dos SANTOS

Mestre em Gestão e Saúde na Amazônia pela Fundação Santa Casa de Misericórdia do Pará (FSCMPA) associado à Universidade Federal do Pará (UFPA) e a Universidade do Estado do Pará (UEPA). Pós-Graduação em Saúde Pública Administração e Planejamento em Projetos Sociais e Auditoria em Serviços de Saúde. Graduada em Serviço Social e Administração. Docente na Faculdade Pan Amazônica (FAPAN), no Programa Nacional de Acesso ao Ensino Técnico e Emprego (PRONATEC) e no Serviço Nacional de Aprendizagem Industrial (SENAI).

E-mail:mcrisjsantos@gmail.com 